\title{
The effect of a bonding agent and thermo- mechanical cycling on the bond strength of a glass-ceramic to gold and cobalt-chromium alloys
}

\author{
Flávia Zardo Trindade ${ }^{1,2^{*}}$, Lilian Costa Anami ${ }^{1}$, Júlia Magalhães da Costa Lima', \\ Luis Gustavo Oliveira de Vasconcellos ${ }^{1}$, Ivan Balducci ${ }^{1}$, Lafayette Nogueira Júnior ${ }^{1}$ and Marco Antonio Bottino ${ }^{1}$
}

\author{
* Correspondence: \\ flaviazardo@hotmail.com \\ ${ }^{1}$ Institute of Science and \\ Technology, UNESP-Univ Estadual \\ Paulista, São José dos Campos, José \\ Longo, 777, São Dimas, São José \\ dos Campos, Brazil \\ ${ }^{2}$ Department of Implantology, \\ School of Dentistry, University of \\ Santo Amaro, São Paulo, Brazil
}

\begin{abstract}
To evaluate the effects of bonding agent and thermo-mechanical cycling on the flexural bond strength of a gold and cobalt-chromium alloy to a feldspathic ceramic. Sixty-four metal bars were fused $\left(3 \times 25 \times 0.5 \mathrm{~mm}^{3}\right)$ : 32 with a gold alloy and 32 with a cobalt-chromium (Co-Cr) alloy. Over the bars' central area $\left(8 \times 3 \mathrm{~mm}^{2}\right)$, a bonding agent and two glass-ceramic layers were fired, totaling $1 \mathrm{~mm}$ in ceramic thickness. Eight specimens of each alloy were randomly divided according to the bonding agent (application or the absence thereof) and the thermo-mechanical cycle (3,000 thermo-cycles and 20,000 mechanical-cycles; or no cycling). The flexural bond strength between the metal alloy and the ceramic was evaluated by a three-point bending test and data were subjected to three-way ANOVA and Tukey's test $(a=0.05)$. The failure mode was classified. No significant interactions were observed among the three factors evaluated (alloy, bonding agent, and thermo-mechanical cycling; $p=0.5734)$. There was no statistically significant difference between the alloys ( $p=0.8559)$. The interaction between alloy/bonding agent $(p=0.0001)$ showed that, for the gold alloy, the group with the bonding agent showed mean values of flexural bond strength significantly higher than those of the group without the bonding agent, while, for the Co-Cr alloy, the groups with or without bonding agent had similar mean values of flexural bond strength. The interaction between alloy/thermo-mechanical cycling $(p=0.0001)$ showed that, for the gold alloy, the non-cycled group had flexural bond strength mean values significantly greater than those of the cycled group, while for the Co-Cr alloy, both non-cycled and cycled groups had similar mean values. The bonding agent significantly improved the flexural bond strength between the ceramic and the gold alloy, but had no influence on the Co-Cr alloy. Thermo-mechanical cycling decreased the flexural bond strength of the gold alloy specimens, but did not affect the Co-Cr specimens.
\end{abstract}

Keywords: Dental Materials; Gold Alloys; Chromium Alloys; Ceramics

\section{Background}

The metal-ceramic system (porcelain fused to metal-PFM) has been the most commonly used indirect restorative treatment since its introduction in dentistry [1,2]. The noble alloys used for the infrastructure of metal-ceramic restorations have high biocompatibility, good mechanical properties, and excellent bonding to veneering ceramic. However, the high cost of noble alloys has limited their use [3], concomitantly causing

\section{严 Springer}

(c) 2014 Trindade et al.; licensee Springer. This is an Open Access article distributed under the terms of the Creative Commons Attribution License (http://creativecommons.org/licenses/by/2.0), which permits unrestricted use, distribution, and reproduction in any medium, provided the original work is properly credited. 
the development and the increased use of basic alloys for the manufacture of crowns and FPD infrastructures.

The cobalt-chromium (Co-Cr) alloys became popular due to their low toxicity and good mechanical properties, such as adequate resistance to permanent deformation and high modulus of elasticity [4-7]. However, the difficulty in controlling chromium oxide $\left(\mathrm{Cr}_{2} \mathrm{O}_{3}\right)$ layer formation at high temperatures remains a drawback of this basic alloy, negatively affecting the bonding between metal and aesthetic veneering ceramic [7]. Therefore, the longevity of metal-ceramic restorations might be dependent of the bond strength between the ceramic and the metallic infrastructure.

Some surface treatments have been studied and the use of an intermediate bonding agent is one of them [8-10]. The bonding agent is the layer of a PFM system interposed between the metal substructure and the outer aesthetic layers. Its primary functions are to create an adequate reflective absorbing layer covering the metal, and also to provide good bonding between the metal infrastructure and the porcelain [11]. The bonding agent materials available on the market are delivered by different application methods and techniques. Such materials are ceramics with higher metal oxide concentrations than body or incisal ceramics [12]. However, the literature is controversial regarding the benefit of these materials for the bond strength between metal and ceramic. According to Lehner and Holtan (1988) [9] and Wood, Thompson and Agar (2007) [10], the use of these agents may be unnecessary for some alloys.

The longevity of restorations can be also damaged by adverse conditions found in the oral environment, such as the chewing cycle and the temperature changes caused by food intake. To approximate the conditions of in vitro studies to in vivo conditions, several laboratory studies [13-17] have used combinations of thermal and mechanical cycling to provide aging to the specimens. Generally, during mechanical cycling, a load is applied on the specimens repeatedly, simulating chewing cycles $[18,19]$, while in the thermal cycling, sudden and extreme changes in temperature are intended to simulate a hostile oral environment for the dental materials [20].

Although the effect of fatigue conditions on flexural bond strength of ceramics to basic metal and gold alloys has been verified by several studies [13,14,16,17,21-23], there is no investigation concerning about the combined effect of a bonding agent and the thermo-mechanical cycling on the bond strength of dental ceramics to metal alloys. Therefore, the present study aimed to evaluate the in vitro influence of a bonding agent and thermo-mechanical cycling on the flexural bond strength between a ceramic and a gold or cobalt-chromium alloy. The study hypotheses were that alloy types produce similar flexural bond strength values, the bonding agent increases the flexural bond strength between ceramic and metal, and thermo-mechanical cycling reduces flexural bond strength values.

\section{Methods}

\section{Fabrication of metallic bars}

Rectangular acrylic templates $\left(27 \times 3 \times 0.5 \mathrm{~mm}^{3}\right)$ were used for the fabrication of the bars. Wax sprues (Horus, Herpo Produtos Dentários Ltd, São Paulo, Brazil) were perpendicularly attached at one end of the template and connected to a 5-mm-diameter central wax rod (Wax Wire for Casting Sprues, Dentaurum, Pforzheim, Germany). The 
assembly was mounted in a silicone ring and filled with investment material (Bellavest ${ }^{\bullet}$ T, Bego, Bremen, Germany). After the investment material set, the silicone ring and the sprue former were separated from the investment mold.

The metallic bars were cast in Co-Cr (Wirobond ${ }^{\circ} \mathrm{C}$, Bego) $(\mathrm{N}=32)$ or in gold alloy (Olympia-Jelenko, Heraeus Kulzer, Hanau, Germany) $(\mathrm{N}=32)$ in an electrical induction furnace (Fornax $\mathrm{GEU}^{\circ}$, Bego) under argon gas. The sprues were eliminated, and the metallic strips were separated by the use of carbide discs at low speed. After the bars were removed from the investment material, their margins were trimmed to final dimensions of $25 \times 3 \times 0.5 \mathrm{~mm}^{3}$ [24], with the measurements controlled by means of a 0.01-mm precision digital caliper (Model Starrett 727, Starrett, Itu, Brazil).

One side of each metallic bar was randomly selected, and its metallic surface was roughened with a cylindrical aluminum oxide white stone (Shofu, Menlo Park, NJ, USA) and a tungsten bur (Edenta 5720.040, Labordental, São Paulo, Brazil) in one direction parallel to the bar's long axis, according to the VM13 ceramic manufacturer's instructions.

Air-particle abrasion with $\mathrm{Al}_{2} \mathrm{O}_{3}$ was standardized through a specially developed device, which maintained the metallic bars at a previously selected distance $(20 \mathrm{~mm})$ and at a $90^{\circ}$ angle between the sandblaster nozzle and the metal bar [14]. The metallic bars were then ultrasonically cleaned in isopropyl alcohol (Vitasonic II, Vita Zahnfabrik, Bad Säckingen, Germany) for $10 \mathrm{~min}$ and dried at room temperature.

\section{Ceramic layer application}

The metallic bars were divided into 4 groups $(n=16)$ according to the alloy and intermediate bonding agents (Table 1). Prior to opaque application, only gold bars were oxidized without vacuum, from 650 to $1010^{\circ} \mathrm{C}$, in a porcelain furnace (Vacumat 40, Vita Zahnfabrik). An area of $8 \times 3 \mathrm{~mm}^{2}$ was initially marked on the Co-Cr and the gold bars with a graphite pencil.

On half of the metallic bars $(\mathrm{n}=32)$, a brush was used to apply a thin layer of bonding agent (VM 13 Wash Opaque, Vita Zahnfabrik, \# 15790) (WO) to the surface delimited by the metal device $[13,14]$, while the other half did not receive the opaque layer.

Then, the opaque ceramic (Opaque Vita VM 13, Vita Zahnfabrik, \#28940) was applied in the form of pulverized powder and liquid, homogenized in a container connected to a dispenser. The thickness $(1 \mathrm{~mm})$ of the ceramic layer (2M2, Vita VM 13, Vita Zahnfabrik, \#10770) was standardized by the positioning of the bars in a metallic device.

After removal from the assembly, the ceramic was fired. Due to shrinkage, a second layer was applied, and the specimens were submitted to a final glaze firing [25].

Table 1 Experimental groups, alloys and bonding agents

\begin{tabular}{ccc}
\hline Groups & Alloy & Bonding agent \\
\hline G1 & Gold & Wash Opaque application \\
G2 & & No Wash Opaque application \\
G3 & Co-Cr & Wash Opaque application \\
G4 & & No Wash Opaque application \\
\hline
\end{tabular}




\section{Mechanical and thermal cycling}

Thirty-two specimens for each surface treatment, gold or $\mathrm{Co}-\mathrm{Cr}$ combinations, were randomly divided into two subgroups: one subjected to mechanical and thermal cycling, and the other one was stored in distilled water for $24 \mathrm{~h}$ at $37^{\circ} \mathrm{C}$ (control group) prior to the flexural strength test. The mechanical cycling was performed in a mechanical stress simulator (Model ER-11000, ERIOS, São Paulo, Brazil). Twenty thousand cycles were performed, with a 1 cycle/sec of frequency and a constant load of $10 \mathrm{~N}$ [16]. During the cycling, the bars remained immersed in distilled water at a controlled temperature of $37^{\circ} \mathrm{C}$. Then, the specimens were thermo-cycled for 3000 cycles between $5 \pm 1$ and $55 \pm 1^{\circ} \mathrm{C}$ in deionized water (Nova Etica, São Paulo, Brazil). The dwell time at each temperature was $10 \mathrm{sec}$, and the transfer time from one bath to the other was 5 sec. Those specimens stored in distilled water were tested without thermo-mechanical cycling after the 24-hour period.

\section{Flexural bond strength test}

The "flexural bond strength" term frequently used to predict the bond strength between metal alloys and the veneering ceramic using a flexural strength test. The threepoint flexural strength test is the recommended test by the International Organization for Standardization to evaluate the metal/ceramic bond strength [26].

The flexural bond strength tests were performed in a universal testing machine (DL1000, EMIC, São José dos Pinhais, Brazil), with the load applied at a constant $1.5 \mathrm{~mm} / \mathrm{min}$ speed until fracture (Figure 1). The load leading to the initial separation of materials was obtained in kilogram force (kgf) and converted to Newtons $(\mathrm{N})$, for the calculation of flexural strength according to the following equation:

$$
\text { Flexural Bond Strength }(\mathrm{MPa})=3 \mathrm{Pl} / 2 \mathrm{bd}^{2}
$$

where $\mathrm{P}$ was the maximum load upon fracture $(\mathrm{N}), \mathrm{l}$ the span distance $(\mathrm{mm})$, b the width, and $d$ the thickness of the specimen $(\mathrm{mm})$.

\section{Fracture analysis}

The specimens were analyzed by visual inspection, and representative images were digitally recorded with a camera (Cybershot, Model DSC S85, Sony, Tokyo, Japan) connected to a stereomicroscope (Stemi 2000-C, Carl Zeiss, Göttingen, Germany), under

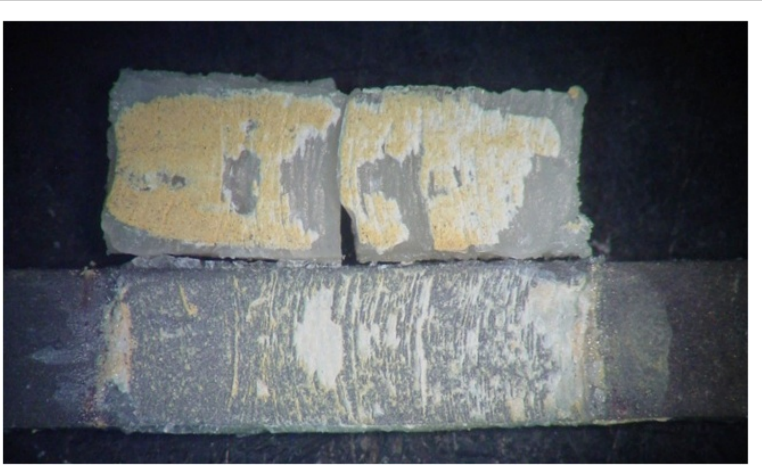

Figure 1 Optical microscopic images of a gold alloy with bonding agent application (G1) after a flexural bond strength test, showing opaque layer remnants on the gold surface (mixed failure). 
30x magnification, to characterize the metal surfaces and the failure modes. The failure types were classified as: adhesive, along the interfacial region between the opaque ceramic and the metal; cohesive, inside the metal; cohesive, inside the ceramic; or a mixture of adhesive failure between the opaque ceramic and the metal, with cohesive fracture of the ceramic.

\section{Statistical analysis}

Statistical analysis was performed using Minitab version 14.12, 2004 (Minitab, Inc., State College, PA, USA) and Statistix for Windows (Analytical Software Inc., Version 8.0, 2003, Tallahassee, FL, USA). A three-factor ANOVA was used to assess the effects of the type of alloy, intermediate bonding agent, and thermo-mechanical cycling on the flexural bond strength. Tukey's test was used for multiple comparisons. The level of significance was set at 5\%. The assumptions of the ANOVA were verified prior to analysis: the residuals were normally distributed, and the plot of the residuals against predicted values indicated homogeneity of variance.

\section{Results}

The means and standard deviations of the experimental groups are described in Table 2. The results of the three-way ANOVA of the experimental conditions are shown in Table 3.

There were no significant interactions among the three studied factors: alloy, bonding agent, and thermo-mechanical cycling $(\mathrm{p}=0.5734)$. The interactions between alloy/ bonding agent and alloy/thermo-mechanical cycling were statistically significant $(\mathrm{p}=$ $0.0001)$. There was no statistically significant difference between the alloys $(\mathrm{p}=0.8559)$.

The Tukey multiple-comparison test results established that when the alloy/bonding agent interaction effect was analyzed, the absence of bonding agent significantly reduced the mean flexural bond strength for the gold alloy, while the Co-Cr alloy groups, with or without bonding agent, had similar flexural bond strength means (Table 4).

Regarding the alloy/thermo-mechanical cycling effect interaction, the results demonstrated that thermo-mechanical cycling significantly reduced the mean flexural bond strength for the gold alloy, while for the $\mathrm{Co}-\mathrm{Cr}$ alloy the mean bond strength values were similar. When the two alloys were compared, it was verified that both had similar flexural bond strength values in the absence and in the presence of thermo-mechanical cycling (Table 5).

Table 2 The mean and standard deviations flexural bond strength values (MPa) for all experimental conditions

\begin{tabular}{lcccr}
\hline Bonding agent & $\begin{array}{c}\text { Mechanico-thermal } \\
\text { cycling }\end{array}$ & \multicolumn{2}{c}{ Alloy } & Mean (SD) \\
\cline { 3 - 5 } & Absence & $50.24 \pm 4.19$ & $40.62 \pm 5.88$ & $45.43 \pm 6.99$ \\
Wash opaque & & $37.26 \pm 6.94$ & $38.65 \pm 5.03$ & $37.95 \pm 5.90$ \\
No wash opaque & Presence & $40.29 \pm 5.23$ & $37.75 \pm 6.97$ & $39.02 \pm 6.09$ \\
Wash opaque & & $24.71 \pm 3.30$ & $36.56 \pm 8.49$ & $30.63 \pm 8.72$ \\
No wash opaque & & $38.12 \pm 10.45$ & $38.40 \pm 6.56$ & \\
Mean (SD) & & & & \\
\hline
\end{tabular}


Table 3 Results of three-way ANOVA for the data obtained by experimental conditions

\begin{tabular}{lccccc}
\hline Effects & DF & SS & MS & $\boldsymbol{F}$ & $\boldsymbol{p}$ \\
\hline Alloy & 1 & 1.18 & 1.18 & 0.03 & 0.8559 \\
Bonding agent & 1 & 1007.27 & 1007.27 & 28.33 & $0.0001^{*}$ \\
Mechanico-thermal cycling & 1 & 753.91 & 753.91 & 21.20 & $0.0001^{*}$ \\
Alloy/bonding agent & 1 & 645.29 & 645.29 & 18.15 & $0.0001^{*}$ \\
Alloy/mechanico-thermal cycling & 1 & 307.56 & 307.56 & 8.65 & $0.0047^{*}$ \\
Bonding agent/mechanico-thermal cycling & 1 & 3.32 & 3.32 & 0.09 & 0.7610 \\
Alloy/bonding agent/mechanico-thermal cycling & 1 & 11.41 & 11.41 & 0.32 & 0.5734 \\
Error & 56 & 1991.02 & 35.55 & & \\
Total & 63 & 4720.97 & & & \\
\hline
\end{tabular}

*Statistically significant difference at the level of $5 \%$.

DF, degrees of freedom; SS, sum of squares; MS, mean ratio square; F, probability; $p, p$-value.

Under visual inspection, most specimens exhibited an opaque layer and ceramic on the surface of the metal, suggesting a mixture of adhesive failure between the opaque ceramic and the metal, with cohesive fracture of the ceramic (Table 6). Only a few specimens showed primarily adhesive failure along the metal/ceramic interface, without the visual presence of ceramic on the metallic surface. A visible dark oxide layer was observed on all specimens. No totally cohesive failures of the metal or the ceramic were observed.

Stereomicroscopic images representing the surfaces of the metal and the ceramic of all groups, after the three-point flexural strength test, are illustrated in Figures 1, 2, 3 and 4 .

\section{Discussion}

This study evaluated the flexural bond strength of a gold alloy (Olympia, Jelenko) and a chromium-cobalt alloy (Wirobond C, Bego) to a veneering feldspathic ceramic (Vita VM 13, Vita Zahnfabrik), in the presence or absence of a bonding agent (Wash Opaque, Vita Zahnfabrik) and with or without the aging of the samples. The results showed no significant difference between the studied alloys, in agreement with the results of recent studies [10,14]. Wood, Thompson and Agar (2007) [10] compared the bond strength of two ceramics and two alloys (a basic and a gold), by means of a bending test, and found that the alloy type had no significant effect. Oliveira de Vasconcellos, et al. (2011) [14] observed the effect of $\mathrm{Al}_{2} \mathrm{O}_{3}$ particle-blasting using the same materials (alloys and ceramics) and methodology as used in this study, and found that the flexural bond strength values were similar to those of the gold and $\mathrm{Co}-\mathrm{Cr}$ alloys.

Table 4 Tukey (5\%) test for flexural bond strength values (MPa) for interaction between alloy and bonding agent

\begin{tabular}{|c|c|c|c|c|}
\hline Alloy & Bonding agent & Mean & & Groups \\
\hline Gold & Presence & 45.27 & A & \\
\hline $\mathrm{Co}-\mathrm{Cr}$ & Presence & 39.19 & & B \\
\hline $\mathrm{Co}-\mathrm{Cr}$ & Absence & 37.60 & & B \\
\hline Gold & Absence & 30.98 & & \\
\hline
\end{tabular}


Table 5 Tukey $(5 \%)$ test for flexural bond strength values ( $\mathrm{MPa}$ ) for interaction between alloy and mechanico-thermal cycling

\begin{tabular}{|c|c|c|c|c|c|}
\hline Alloy & Mechanico-thermal cycling & Mean & & Groups & \\
\hline Gold & Absence & 43.75 & A & & \\
\hline $\mathrm{Co}-\mathrm{Cr}$ & Absence & 39.64 & A & B & \\
\hline $\mathrm{Co}-\mathrm{Cr}$ & Presence & 37.16 & & B & C \\
\hline Gold & Presence & 32.50 & & & C \\
\hline
\end{tabular}

Different methods and application techniques for the opaque ceramic layer have been tested to verify the ideal bond between metal and ceramic [10,11,13,27-29]. In the present study, the opaque ceramic used was applied in two steps, being the Wash Opaque (WO) applied first, and then, the opaque (OP). Wash Opaque and the respective opaque material are available for the wash back and have the same chemicalphysical properties [25]. The Wash Opaque layer functions to form the oxides required for adhesion between alloy and ceramic, to prepare for the bonding to the alloy surface, and to increase the chroma of the restoration, especially in basic alloys [25], and can be characterized as a bonding agent.

In this study, the two alloys were tested in the presence and absence of the bonding agent, and its presence improved flexural bond strength values for specimens from the gold alloy group, whereas for the $\mathrm{Co}-\mathrm{Cr}$ alloy specimens, the presence or absence of the Wash Opaque layer did not affect flexural bond strength values. Wood, Thompson and Agar (2007) [10] compared the flexural bond strength of two ceramics and two alloys (a basic and a gold) with and without the application of an opaque ceramic layer, obtaining results similar to those of this study. They concluded that the presence of the opaque ceramic generally increased the bond strength to the ceramic systems tested; however, the magnitude varied with the alloy/ceramic combination, and the opaque ceramic layer application may not be necessary for some metal-ceramic systems.

To simulate the harsh conditions of the oral environment, several studies have used combinations of thermal and mechanical cycling [13-17]. Mechanical cycling aims to reproduce the effects of repetitive masticatory loads $[18,19]$, to determine the survival of the restorative material over time. During this simulation, cracks or wear surfaces can contribute to the deterioration of the material [20]. Thermal cycling, with its successive temperature changes during water immersion, induces repeated stress that weakens the bond between metal and ceramics, due to the difference between these materials' coefficients of thermal expansion [16].

In the present study, half of the samples were subjected to thermo-mechanical cycling, and the results demonstrated that this significantly reduced the flexural bond

Table 6 Incidence of failure types (\%) after flexural bond strength test

\begin{tabular}{lcc}
\hline Experimental groups $(\mathbf{n}=\mathbf{6 4})$ & \multicolumn{2}{c}{ Failure types } \\
\cline { 2 - 3 } & Adhesive & Mixed \\
\hline G1-Gold/Bonding agent & $12.5(2)$ & $87.5(14)$ \\
G2-Gold/ No bonding agent & $25(4)$ & $75(12)$ \\
G3-Co-Cr/Bonding agent & $6.25(1)$ & $93.75(15)$ \\
G4-Co-Cr /No bonding agent & $25(4)$ & $75(12)$ \\
\hline
\end{tabular}

*Adhesive-along the interfacial region between the opaque ceramic and the metal; Mixed-mixture of adhesive failure between the opaque ceramic and the metal with cohesive fracture of the ceramic. 


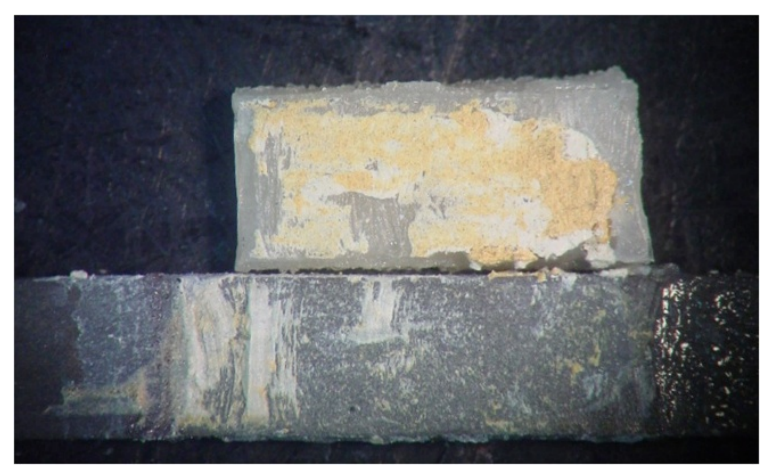

Figure 2 Optical microscopic images of a gold alloy without bonding agent application (G2) after flexural bond strength test, showing opaque layer remnants on the gold surface (mixed failure).

strength values for the gold alloy specimens, whereas, for the Co-Cr specimens, it decreased the flexural bond strength values, but without statistically significant differences. These results for the gold alloy group corroborate the results of other studies $[14,16,17]$, which used the same conditions of thermo-mechanical cycling. Moreover, de Vasconcellos, et al. (2010) [13] examined the influence of temperature firing of the opaque layer and thermo-mechanical cycling on flexural bond strength between a ceramic and a Co-Cr alloy, and observed that the thermo-mechanical cycling did not significantly influence the bond strength between the ceramic and the basic alloy. Similar results were found by Tróia et al. (2003) [13,21]. The Co-Cr alloy was not significantly influenced by both the effect of the presence or absence of the Wash Opaque bonding agent, and the presence or absence of thermo-mechanical cycling. One possible explanation for this phenomenon may be the difference between the opaque layer firing temperature when the ceramic (Vita VM 13) is applied to a basic metal (Wash Opaque at $940^{\circ} \mathrm{C}$ and opaque ceramic at $920^{\circ} \mathrm{C}$ ) and when the same ceramic is applied to noble metals (Wash Opaque at $890^{\circ} \mathrm{C}$ and opaque ceramic at $890^{\circ} \mathrm{C}$ ). In addition, previous studies $[13,28]$ evaluating the effect of increasing the firing temperature of the opaque layer on the bond strength between metal and ceramics have found that increasing this temperature improved the strength between metal and ceramic. The technique of increasing this temperature is based on the hypothesis that there is an increase in electron transference between the glass and metal oxides [29]. On the other hand, Vojdani

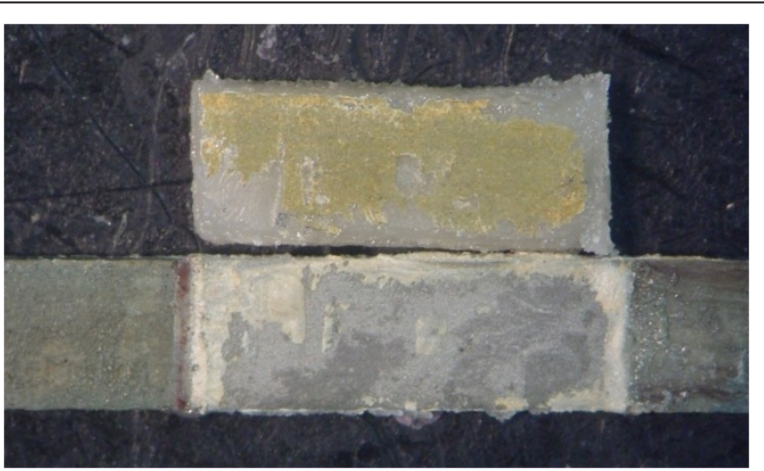

Figure 3 Optical microscopic images of a Co-Cr alloy with bonding agent application (G3) after flexural bond strength test, showing opaque layer remnants on metal surface (mixed failure). 


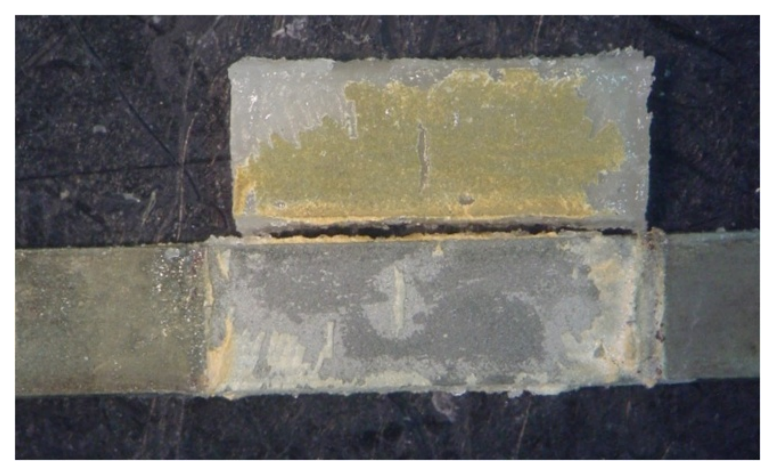

Figure 4 Optical microscopic images of a Co-Cr alloy without bonding agent application (G4) after flexural bond strength test, showing opaque layer remnants on metal surface (mixed failure).

et al. (2012) [23] evaluates in a recent study the effect of thermo-mechanical cycling (TMC) on the bond strength of a ceramic to three cobalt-chromium (Co-Cr) and two nickel-chromium (Ni-Cr) alloys, and they observed the thermo-mechanical fatigue condition decreases the bond strength of $\mathrm{Ni}-\mathrm{Cr}$ and $\mathrm{Co}-\mathrm{Cr}$ alloys to the ceramic. However, the authors affirmed the tested metal-ceramic systems still show sufficient bond strength for clinical performance of the restorations and the effect of thermo-mechanical cycling was relatively the same for all the tested base metal-ceramic systems.

Mechanical tests such as the tensile [30], shear [3,31,32], three-point bending [14-16], and four-point bending [11] can be applied to compare or quantify the bond strength between metals and ceramics, and there is no consensus in the literature regarding the most indicated test to evaluate the bond strength between these two materials [33,34]. Della Bona and Van Noort [35] purposed a study using the shear bond strength test and they observed that this kind of test created cohesive fractures into the ceramic in all the samples, because of the highly non-uniform tension distribution on the interface of the materials [35]. However, since the specimens are simultaneously submitted to shearing, tensile, and compression forces during the flexural strength or bending test, this test seems to be the most indicated to simulate the clinical condition [36]. Therefore, the test selected for this study was the three-point bending test, which is also recommended by the International Organization for Standardization [24] to analyze the bond strength between metals and ceramics [26]. According to this standard [24], the appropriate union between a metal and a ceramic occurs when the flexural bond strength value is greater than $25 \mathrm{MPa}$. Only G2 specimens (gold without WO) with thermo-mechanical cycling did not attain an average flexural bond strength value greater than the minimum established by ISO 9693.

The cohesive strength of the ceramic should be overcome by the interfacial bond strength between metal and porcelain [10]. Clinically, if a failure of a metal-ceramic bond should occur, it would be completely within the porcelain, that is a cohesive failure [10]. Analysis of the fracture type revealed that most of the specimens presented mixed fracture: adhesive failure between metal and ceramic, and cohesive failure in the opaque layer and covering ceramic, with the ceramic fragment in contact to the metal. De Vasconcellos, et al. (2011) [14] evaluated the effects of airborne-particle abrasion and thermo-mechanical cycling on the flexural bond strength of a ceramic fused to cobalt-chromium alloy or gold alloy and found a predominance of mixed failures for 
both alloys. Additionally, according to Papazoglou and Brantley (1998) [37], this provides evidence for the excellent bond strength between the metal and the ceramic.

Regarding the longevity of metal-ceramic restorations can be dependent of the bond strength between the ceramic and the metallic infrastructure, investigating the effect of a bonding agent on the bond strength of dental ceramics to base metal alloys in an aging situation seems to be an important topic to study; especially because this type of restoration is one of the most commonly used treatments in dental offices and failures by ceramic debonding from metal is still recurring. However, besides the relevance of the results of in vitro studies, longitudinal clinical trials are also required to investigate the behavior of these materials in PFM restorations in the clinical situation.

\section{Conclusions}

Based on the results and considering the levels used in this study, it can be conclude that:

(1) Using the Wash Opaque improved the flexural bond strength between the ceramic and the gold alloy, however no influence was observed when used on the cobaltchromium alloy; and

(2) Thermo-mechanical cycling decreased the flexural bond strength of specimens with the gold alloy, but did not affect those with the Co-Cr alloy.

Competing interests

The authors declare that they have no competing interests.

\section{Authors' contributions}

FZT and LCA planned the project and methodology, executed part of the methodology and wrote the paper. JMCL executed part of methodology and wrote the paper. LGOV got the idea and corrected the final version of the manuscript. IB executed the statistical analyses. LNJ and MAB guided the conception idea, the project planning and raised funds to do the study. All authors read and approved the final manuscript.

Received: 19 November 2013 Accepted: 17 December 2013

Published: 2 September 2014

References

1. Deger S, Caniklioglu MB (1998) Effects of tin plating on base metal alloy-ceramic bond strength. Int J Prosthodont 11(2):165-172

2. Graham JD, Johnson A, Wildgoose DG, Shareef MY, Cannavina G (1999) The effect of surface treatments on the bond strength of a nonprecious alloy-ceramic interface. Int J Prosthodont 12(4):330-334

3. Akova T, Ucar Y, Tukay A, Balkaya MC, Brantley WA (2008) Comparison of the bond strength of laser-sintered and cast base metal dental alloys to porcelain. Dent Mater 24(10):1404. doi:10.1016/j.dental.2008.03.001

4. Atsu S, Berksun S (2000) Bond strength of three porcelains to two forms of titanium using two firing atmospheres. J Prosthet Dent 84(5):567-574. doi:10.1067/mpr.2000.110267

5. Kelly JR, Rose TC (1983) Nonprecious alloys for use in fixed prosthodontics: a literature review. J Prosthet Dent 49(3):363-370

6. MacEntee MI, Hawbolt EB, Zahel J (1981) The tensile and shear strength of a base metal weld joint used in dentistry. J Dent Res 60(2):154-158

7. Wu Y, Moser JB, Jameson LM, Malone WF (1991) The effect of oxidation heat treatment of porcelain bond strength in selected base metal alloys. J Prosthet Dent 66(4):439-444

8. Gavelis JR, Lim SB, Guckes AD, Morency JD, Sozio RB (1982) A comparison of the bond strength of two ceramometal systems. J Prosthet Dent 48(4):424-428

9. Lehner CR, Holtan JR (1988) A comparison of the bond strength of opaque and body porcelains on different types of ceramo-metal alloys. Schweiz Monatsschr Zahnmed 98(9):937-943

10. Wood MC, Thompson GA, Agar JR (2007) A comparison of debonding strengths of four metal-ceramic systems with and without opaque porcelain. J Prosthet Dent 97(3):141-149. doi:10.1016/j.prosdent.2006.12.013

11. Jorn D, Waddell JN, Swain MV (2010) The influence of opaque application methods on the bond strength and final shade of PFM restorations. J Dent 38(Suppl 2):e143-e149. doi:10.1016/j.jdent.2010.08.016

12. Anusavice KJ (2003) Phillips science of dental materials. Saunders, Philadelphia

13. de Vasconcellos LG, Buso L, Lombardo GH, Souza RO, Nogueira L, Jr, Bottino MA, Ozcan M (2010) Opaque layer firing temperature and aging effect on the flexural strength of ceramic fused to cobalt-chromium alloy. J Prosthodont 19(6):471-477. doi:10.1111/j.1532-849X.2010.00600.x 
14. Oliveira de Vasconcellos LG, Silva LH, Reis de Vasconcellos LM, Balducci I, Takahashi FE, Bottino MA (2011) Effect of airborne-particle abrasion and mechanico-thermal cycling on the flexural strength of glass ceramic fused to gold or cobalt-chromium alloy. J Prosthodont 20(7):553-560. doi:10.1111/j.1532-849X.2011.00761.X

15. Fischer J, Zbaren C, Stawarczyk B, Hammerle CH (2009) The effect of thermal cycling on metal-ceramic bond strength. J Dent 37(7):549-553. doi:10.1016/j.jdent.2009.03.014

16. Oyafuso DK, Ozcan M, Bottino MA, Itinoche MK (2008) Influence of thermal and mechanical cycling on the flexural strength of ceramics with titanium or gold alloy frameworks. Dent Mater 24(3):351-356. doi:10.1016/j. dental.2007.06.008

17. Vasquez V, Ozcan M, Nishioka R, Souza R, Mesquita A, Pavanelli C (2008) Mechanical and thermal cycling effects on the flexural strength of glass ceramics fused to titanium. Dent Mater J 27(1):7-15

18. Itinoche KM, Ozcan M, Bottino MA, Oyafuso D (2006) Effect of mechanical cycling on the flexural strength of densely sintered ceramics. Dent Mater 22(11):1029-1034. doi:10.1016/j.dental.2005.11.025

19. Scherrer SS, Wiskott AH, Coto-Hunziker V, Belser UC (2003) Monotonic flexure and fatique strength of composites for provisional and definitive restorations. J Prosthet Dent 89(6):579-588. doi:10.1016/S0022391303001744

20. Rosentritt M, Behr M, van der Zel JM, Feilzer AJ (2009) Approach for valuating the influence of laboratory simulation. Dent Mater 25(3):348-352. doi:10.1016/j.dental.2008.08.009

21. Troia MG, Jr, Henriques GE, Nobilo MA, Mesquita MF (2003) The effect of thermal cycling on the bond strength of low-fusing porcelain to commercially pure titanium and titanium-aluminium-vanadium alloy. Dent Mater 19(8):790-796

22. Madhav VN, Padmanabhan TV, Subramnian R (2012) Evaluation of flexural bond strength of porcelain to used nickel-chromium alloy in various percentages. Indian J Dent Res 23(1):11-14. doi:10.4103/0970-9290.99030

23. Vojdani M, Shaghaghian S, Khaledi A, Adibi S (2012) The effect of thermal and mechanical cycling on bond strength of a ceramic to nickel-chromium (Ni-Cr) and cobalt-chromium (Co-Cr) alloys. Indian J Dent Res 23(4):509-513. doi:10.4103/0970-9290.104960

24. Standardization, International Organization of (1999) Metal-ceramic dental restorative systems. Geneva.

25. Vita VM13 Working instructions. http://vident.com/wp-content/uploads/2008/12/NM13_instructions_0411.pdf. Accessed 20112014

26. Lenz J, Schwarz S, Schwickerath H, Sperner F, Schafer A (1995) Bond strength of metal-ceramic systems in threepoint flexure bond test. J Appl Biomater 6(1):55-64. doi:10.1002/jab.770060108

27. Rake PC, Goodacre CJ, Moore BK, Munoz CA (1995) Effect of two opaquing techniques and two metal surface conditions on metal-ceramic bond strength. J Prosthet Dent 74(1):8-17

28. Wight TA, Bauman JC, Pelleu GB, Jr (1977) An evaluation of four variables affecting the bond strength of porcelain to nonprecious alloy. J Prosthet Dent 37(5):570-577

29. Daftary F, Donovan T (1986) Effect of four pretreatment techniques on porcelain-to-metal bond strength Prosthet Dent 56(5):535-539

30. Bullard JT, Dill RE, Marker VA, Payne EV (1985) Effects of sputtered metal oxide films on the ceramic-to-metal bond. J Prosthet Dent 54(6):776-778. doi: 0022-3913(85)90468-8

31. Bondioli IR, Bottino MA (2004) Evaluation of shear bond strength at the interface of two porcelains and pure titanium injected into the casting mold at three different temperatures. J Prosthet Dent 91(6):541-547. doi:10.1016/S002239130400188XS002239130400188X

32. Lombardo GH, Nishioka RS, Souza RO, Michida SM, Kojima AN, Mesquita AM, Buso L (2010) Influence of surface treatment on the shear bond strength of ceramics fused to cobalt-chromium. J Prosthodont 19(2):103-111. doi:10.1111/j.1532-849X.2009.00546.X

33. Caputo AA (1978) Effect of surface preparation on bond strength of nonprecious and semi-precious alloys. CDA J 6(11):42-46

34. DeHoff PH, Anusavice KJ, Hathcock PW (1982) An evaluation of the four-point flexural test for metal-ceramic bond strength. J Dent Res 61(9):1066-1069

35. Della Bona A, van Noort R (1995) Shear vs. tensile bond strength of resin composite bonded to ceramic. J Dent Res 74(9):1591-1596

36. Anusavice KJ (1996) Phillips' Science of Dental Materials. Saunders, Philadelphia

37. Papazoglou E, Brantley WA (1998) Porcelain adherence vs force to failure for palladium-gallium alloys: a critique of metal-ceramic bond testing. Dent Mater 14(2):112-119

doi:10.1186/2196-4351-2-16

Cite this article as: Trindade et al:: The effect of a bonding agent and thermo-mechanical cycling on the bond strength of a glass-ceramic to gold and cobalt-chromium alloys. Applied Adhesion Science 2014 2:16. 